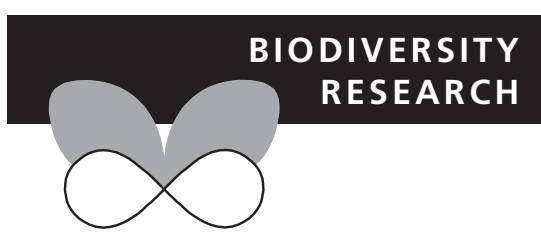

\title{
Using molecular tools to guide management of invasive alien species: assessing the genetic impact of a recently introduced island bird population
}

\author{
J. van de Crommenacker ${ }^{1,2 \star}$, Y. X. C. Bourgeois ${ }^{3}$, B. H. Warren ${ }^{4}$, \\ H. Jackson ${ }^{2}$, F. Fleischer-Dogley ${ }^{1}$, J. Groombridge ${ }^{2}$ and N. Bunbury ${ }^{1}$
}

${ }^{1}$ Seychelles Islands Foundation, La Ciotat Building, Mont Fleuri, Mahé, Victoria, Seychelles, ${ }^{2}$ Durrell Institute of Conservation and Ecology (DICE), School of Anthropology and Conservation, University of Kent, Marlowe Building, Canterbury, Kent, UK, ${ }^{3}$ Zoologisches Institut, Evolutionsbiologie, University of Basel, Vesalgasse 1, 4051 Basel, Switzerland, ${ }^{4}$ Institute of Systematic Botany, University of Zurich, Zollikerstrasse 107, 8008 Zurich, Switzerland

${ }^{\star}$ Correspondence: Janske van de Crommenacker, Seychelles Islands Foundation, La Ciotat Building, Mont Fleuri, Mahé, Victoria, Seychelles.

E-mail: janskevandecrommenacker@ gmail.com

\begin{abstract}
Aim Biological invasions are a major threat to island biodiversity and are responsible for a large proportion of species declines and extinctions worldwide. The process of hybridization between invasive and native species is a major factor that contributes to the loss of endemic genetic diversity. The issue of hybridization is often overlooked in the management of introduced species because morphological evidence of hybridization may be difficult to recognize in the field. Molecular techniques, however, facilitate identification of specific hybridization events and assessment of the direction and timing of introgression. We use molecular markers to track hybridization in a population of an island endemic bird, the Aldabra fody (Foudia aldabrana), following the recent discovery of a co-occurring population of non-native Madagascar fodies (Foudia madagascariensis).
\end{abstract}

Location Aldabra Atoll, Seychelles.

Methods We combine phylogenetic analyses of mitochondrial and nuclear markers to assess whether hybridization has occurred between F. madagascariensis and F. aldabrana on Aldabra. Using coalescence models and comparing different hybridization scenarios, we estimate the timing of such events and confirm the geographic origin of $F$. madagascariensis.

Results Our analyses confirm a recent hybridization event between the two species of Foudia, and we find evidence that the invasive F. madagascariensis originate from the neighbouring island of Assumption, where they were introduced in the 1970s.

Main conclusions Our results validate the threat of losing the unique genetic diversity of $F$. aldabrana through admixture due to recent invasion of $F$. madagascariensis. We show that molecular analyses can be a valuable tool in formulating strategies for the management of invasive birds.

\section{Keywords}

avian conservation, biological invasions, coalescence analyses, fody, hybridization, invasive alien species, mitochondrial and nuclear DNA.

\section{INTRODUCTION}

Biological invasions are key drivers of biodiversity loss (Meffe \& Carroll, 1994; Veitch \& Clout, 2002; Strubbe et al.,
2011). Invasive alien species have contributed substantially to species declines and extinctions, particularly on islands where rates of endemism and susceptibility to threats are high (Vitousek et al., 1995; Veitch \& Clout, 2002; Baker et al., 
2014). The adverse effects of invasive alien species are diverse, with predation (Dowding \& Murphy, 2001), habitat disruption (Atkinson, 1989), competitive exclusion (i.e. resource domination (Hansen et al., 2002; but see Simberloff \& Boecklen, 1991) and transmission of novel pathogens (Hatcher et al., 2012) widely recognized to compromise the survival of native species.

Invasive alien species can also hybridize with native species, leading to the loss of unique genetic diversity (Rhymer \& Simberloff, 1996; Baker et al., 2014). There is abundant documentation of hybridization between bird species (Grant \& Grant, 1992; Fitzpatrick, 2004). In some cases, hybridization can lead to partial to near-total 'genetic extinction' of a native species' genome (i.e. extinction by hybridization) and is therefore a serious concern for threatened or rare native species (Rhymer \& Simberloff, 1996; Baker et al., 2014). However, relatively few studies have so far addressed avian hybridization in the context of species conservation (but see Haig \& Allendorf, 2006; Steeves et al., 2010). The literature is largely restricted to non-passerine birds, such as partridges and ducks (Fowler et al., 2009; McCracken \& Wilson, 2011; Baker et al., 2014), with only a handful of studies on passerines (Ma \& Lambert, 1997; Vallender et al., 2007).

In practice, the issue of hybridization is often undetected or underestimated in invasive species management because hybrids are often unrecognizable in the field, even in their first generation (F1), and especially after some generations (Anderson, 1949; Allendorf et al., 2001; Seehausen, 2004). For example, not all morphological variation has a genetic basis, and hybrids can express a variety of parental phenotypes (Allendorf et al., 2001), both of which can impede identification of hybrids. Morphological evidence of hybridization is particularly difficult to detect when backcrossing has occurred with one or both parental populations (Anderson, 1949; Allendorf et al., 2001; Seehausen, 2004). In the last 15 years, however, advances in analytical tools in genetic research have allowed the timing and magnitude of past gene flow to be inferred with greater confidence (Huelsenbeck et al., 2001; Beaumont et al., 2002; Pavlidis et al., 2010; Csilléry et al., 2012). The use of genetic data to predict hybridization risks to native species after invasions may thus provide critical information for managing and conserving unique ecosystems. Moreover, combining data from maternally inherited mitochondrial DNA and bi-parentally inherited nuclear DNA allows any bias in the direction of gene flow to be evaluated (Rhymer \& Simberloff, 1996), providing a more comprehensive picture of invasion dynamics.

A population of non-native Madagascar fodies (Foudia madagascariensis) was recently discovered on Aldabra Atoll, Seychelles. These birds were thought to originate from the neighbouring island of Assumption (27 km from Aldabra), where they were introduced from Mauritius in 1977 for decorative purposes (Prys-Jones et al., 1981) and then substantially increased in population size (Roberts, 1988). To prevent F. madagascariensis from invading Aldabra, an eradication programme was initiated on Assumption in January
2012 which has since reduced the Madagascar fody population - initially estimated to be $>3000$ birds - by over 99\% (Seychelles Islands Foundation, unpubl. data). Foudia madagascariensis was first recorded in a rarely visited region of Aldabra in March 2012, following intensified monitoring of the area as part of a feral goat eradication programme. The Aldabran population of $F$. madagascariensis has since been the focus of eradication efforts in an attempt to preserve the unique evolutionary trajectory of the endemic Aldabra fody (Foudia aldabrana) (Frith, 1976). The Aldabra fody, with a current population size estimated to be several thousands of individuals, was formerly considered a subspecies of the Comoro redheaded forest fody ( $F$. eminentissima) endemic to Aldabra (named Foudia eminentissima aldabrana). It concomitantly still holds the IUCN Red List status of 'Least Concern' (IUCN 2014) that actually applies to the much more widely distributed F. eminentissima. However, F. aldabrana has recently been raised to full species status (Safford \& Hawkins, 2013); therefore, protecting this taxon's genetic integrity is critical and its Red List status should be reviewed.

Concerns about hybridization were raised in October 2012 after some birds were observed with morphological and behavioural traits of both F. aldabrana and F. madagascariensis. This establishment of F. madagascariensis on Aldabra therefore provides an opportunity to investigate earlystage post-invasion hybridization events between an endemic and an invasive species and to use molecular ecological tools to inform conservation management.

We use a combination of molecular phylogenetic and coalescent approaches to (1) assess whether hybridization has occurred between F. aldabrana and F. madagascariensis on Aldabra; (2) estimate the timing of admixture; and (3) confirm the geographic source of the introduced F. madagascariensis, that is whether they originated from nearby Assumption or from another source population. The results are important for management decisions because natural admixture events could have occurred historically, long before the introduction of F. madagascariensis to Assumption. Because of the close proximity of Assumption to Aldabra (Fig. 1), the strong seasonal south-east trade winds that blow from there towards Aldabra and the added propagule pressure posed by the increasing population density of F. madagascariensis on Assumption, recent arrival from Assumption seems most likely. Given the propensity for interisland colonization in Foudia (Warren et al., 2012), however, other scenarios are biologically plausible and are therefore explored in this study.

\section{METHODS}

\section{Study population, sampling and data collection}

The UNESCO World Heritage site of Aldabra Atoll $\left(9^{\circ} 24^{\prime} \mathrm{S}\right.$, $46^{\circ} 20^{\prime}$ E; Fig. 1$)$ is a large $(34 \times 14.5 \mathrm{~km}$, total land area: $152.6 \mathrm{~km}^{2}$ ) raised coral atoll forming part of the Seychelles in the south-western Indian Ocean. The atoll consists of a ring of four main islands (Grande Terre, Malabar, Picard 


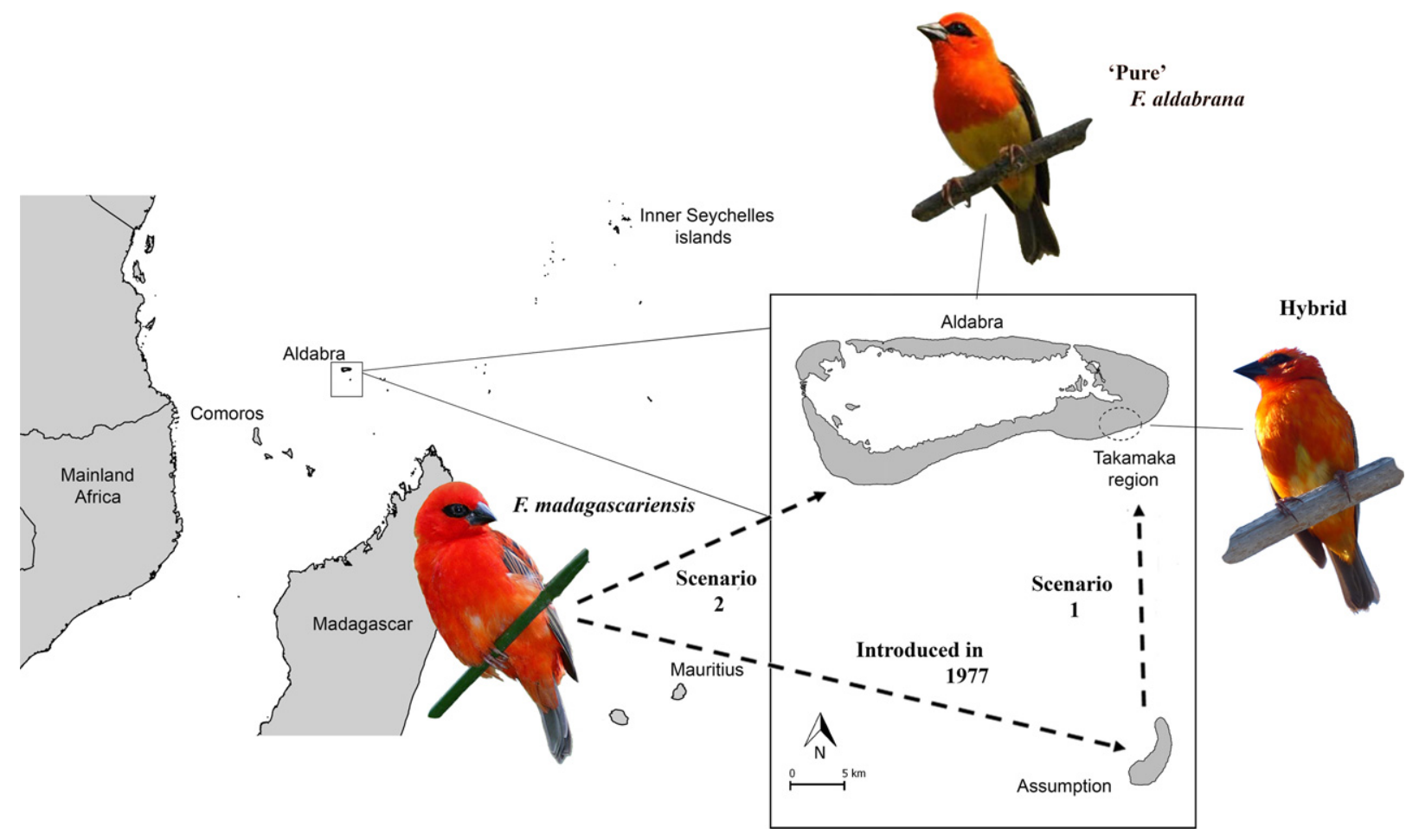

Figure 1 Western Indian Ocean with the location of Aldabra and Assumption (enlarged in inset), Madagascar and Mauritius. Encircled in the inset is the Takamaka invasion area on Aldabra Atoll. Photographs of a 'pure' Aldabra fody, a 'pure' Madagascar fody and a hybrid individual are shown. See the legend of Fig. 2 for a description of the two scenarios.

and Polymnie). Aldabra has no resident human population, has been strictly protected since 1976 and has been managed entirely for research and conservation since 1979 by the Seychelles Islands Foundation (SIF). Aldabra was the world's largest tropical island with an entirely native avifauna until the discovery of F. madagascariensis on Grand Terre in 2012 (Fig. 1). Initial surveys produced estimates of 100-150 F. madagascariensis individuals that were restricted to the area of Takamaka (SIF, unpubl. data). The presence of this likely invasive species was considered a severe threat to Aldabra's avifauna, and an eradication attempt was launched in late March 2012 which is currently ongoing.

Fodies were caught using mist-nets between September 2011 and March 2012 (F. madagascariensis on Assumption and F. aldabrana in other areas than Takamaka, as part of separate research projects) and between March 2012 and March 2014 (both species in Takamaka and F. aldabrana in other areas than Takamaka). Blood samples were taken by brachial venipuncture. Samples were placed in $1 \mathrm{~mL}$ of $96 \%$ ethanol and stored refrigerated. Morphological measurements (body mass, tarsus length, head-bill length, bill width and bill height) were taken. These measurements (Table S1 in Supporting Information) were used by the team as a cue, in combination with visual and behavioural differences, to identify birds as F. aldabrana, F. madagascariensis or putative hybrids (i.e. F1 or recent hybrids). All F. aldabrana were released at the point of capture, and F. madagascariensis and putative hybrids were culled. Sex was confirmed either by plumage (breeding F. aldabrana; Table S1), with molecular methods (non-breeding F. aldabrana; Appendix S1), or by dissection and examination of gonads (F. madagascariensis, putative hybrids).

As signs of hybridization may not be visible from morphology, all fodies caught at Takamaka (birds identified as F. aldabrana: $n=13$, F. madagascariensis: $n=14$ and putative hybrids: $n=32$ ) were treated as potential hybrids in the analyses. Samples of 'pure' F. aldabrana (i.e. those considered to be genetically unaffected by the recent arrival of F. madagascariensis; $n=24$ ) were collected from other Aldabran islands (Picard: $n=12$, Polymnie: $n=9$ and Malabar: $n=6$ ) to provide a genetic reference for $F$. aldabrana. Three F. aldabrana samples (from Picard) used in Warren et al. (2012) were also included. Reference samples of 'pure' $F$. madagascariensis were collected from the suspected source population of Assumption $(n=10)$ and from other islands ( $n=21$; inner Seychelles/Madagascar/other islands from Warren et al., 2012). Furthermore, data from a broad sampling of Ploceidae (weaverbirds) from Africa, Asia and Madagascar, and of other Foudia from the western Indian Ocean were used as reference material from other islands and as phylogenetic outgroups (Warren et al., 2012). To further strengthen the power to diagnose hybrids within the sample set, reference samples were obtained from two confirmed Foudia hybrid offspring along with their parents, a F. madagascariensis (father) and Mauritius fody (Foudia 
rubra; mother) that mated in captivity on Mauritius, together with five 'pure' F. rubra caught in 2006 and 2008 on Ile aux Aigrettes, Mauritius.

\section{Molecular markers}

The following gene regions were selected for amplification (see Table 1 for primers and conditions): mitochondrial: ATP synthase 6 and 8 (ATPase 6\&8; $841 \mathrm{bp}$ ), NADH dehydrogenase subunit 3 (ND3; $382 \mathrm{bp}$ ), nuclear: a region including the intron $\mathrm{A}$ and short sections of the flanking exons of the chromo-helicase-DNA binding protein gene from the Z-chromosome (CHD1Z; $565 \mathrm{bp}$ ), intron 11 of the glyceraldehyde-3-phosphodehydrogenase gene (G3PDH; $288 \mathrm{bp}$ ) and a fragment of the melanocortin-1 receptor gene (MC1R; $716 \mathrm{bp})$. See Appendix S1 for a description of the DNA extraction, PCR protocols and sequencing.

\section{Data partition, model selection and phylogenetic inference}

Foudia mitochondrial data are known to provide phylogenetic signal that conflicts with true lineage history as a result of unidirectional introgression and mitochondrial capture (Warren et al., 2012). Therefore, nuclear and mitochondrial data were analysed separately. The congruence of the regions within the mitochondrial and nuclear datasets was tested using the partition homogeneity $(\mathrm{PH})$ test (Farris et al., 1995) implemented in PAUP* (Swofford, 2003), using simplified subsets with reduced numbers of individuals but including all haplotypes to reduce computation time. For both the mitochondrial and nuclear datasets (SEQuenceMATRIX; Vaidya et al., 2011), the software program PARTITIONFINDER (Lanfear et al., 2012) was used to determine the substitution model which best describes the data.
Figure 2 The two immigration scenarios tested in this study: (a) a recent arrival from Assumption (and therefore time since admixture) between 5 and 37 years ago (scenario 1 ); and (b) a recent-to-ancient arrival from Madagascar (scenario 2). (a)

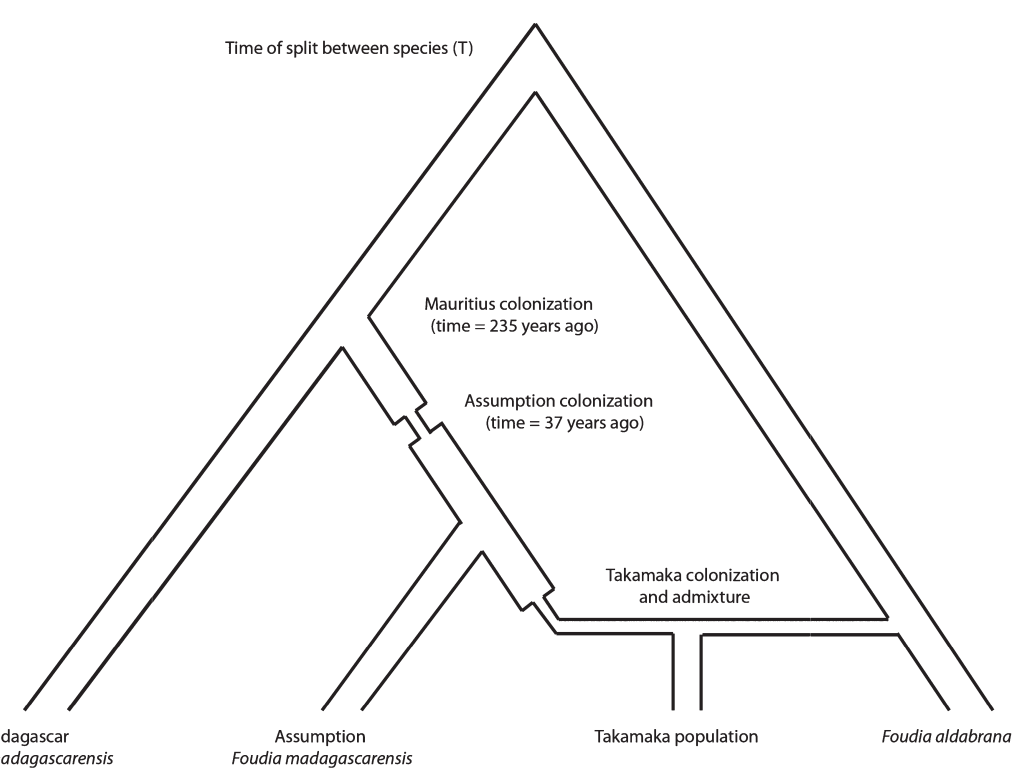

(b)

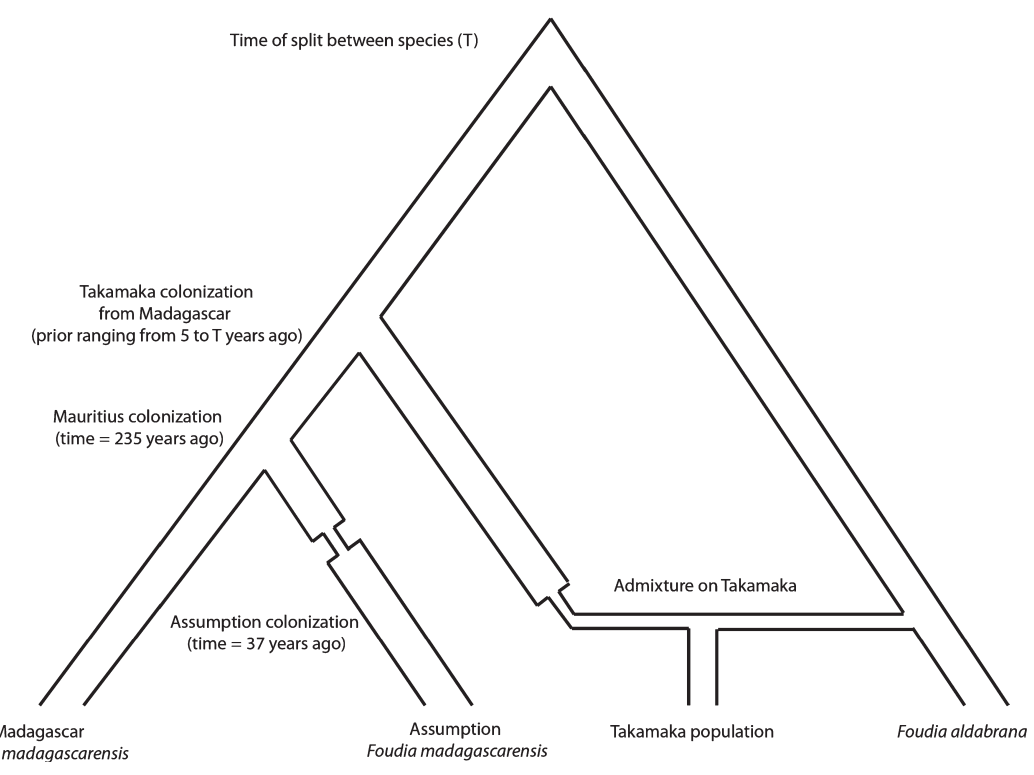


Table 1 Primers and experimental conditions used to amplify and sequence the genes used in this study.

\begin{tabular}{|c|c|c|c|c|c|c|c|}
\hline \multirow[b]{2}{*}{ DNA type } & \multirow[b]{2}{*}{$\begin{array}{l}\text { Gene } \\
\text { region }\end{array}$} & \multirow[b]{2}{*}{ Primer names } & \multirow[b]{2}{*}{ Source } & \multicolumn{4}{|c|}{ PCR conditions* } \\
\hline & & & & $\begin{array}{l}\text { Number } \\
\text { of cycles }\end{array}$ & Denaturation & Annealing & Extension \\
\hline \multirow[t]{2}{*}{$\begin{array}{l}\text { Mitochondrial } \\
\text { DNA }\end{array}$} & $\begin{array}{c}\text { ATPase } \\
6 \& 8\end{array}$ & $\begin{array}{l}\mathrm{CO} 2 \mathrm{GQL} \text { and } \\
\mathrm{CO} 3 \mathrm{HMH}\end{array}$ & Warren et al. (2012) & 30 & $95^{\circ} \mathrm{C}$ for $15 \mathrm{~s}$ & $58^{\circ} \mathrm{C}$ for $15 \mathrm{~s}$ & $72{ }^{\circ} \mathrm{C}$ for $10 \mathrm{~s}$ \\
\hline & ND3 & $\begin{array}{l}\text { L10755 and } \\
\text { H11151 }\end{array}$ & Chesser (1999) & 30 & $95{ }^{\circ} \mathrm{C}$ for $15 \mathrm{~s}$ & $50{ }^{\circ} \mathrm{C}$ for $15 \mathrm{~s}$ & $72{ }^{\circ} \mathrm{C}$ for $10 \mathrm{~s}$ \\
\hline \multirow[t]{4}{*}{ Nuclear DNA } & \multirow[t]{2}{*}{ CHD1Z } & \multirow[t]{2}{*}{$\begin{array}{l}2688 \mathrm{fz} \text { and } \\
2718 \mathrm{r}\end{array}$} & \multirow{2}{*}{$\begin{array}{l}\text { Härlid (pers. comm.) in } \\
\text { Ödeen \& Björklund } \\
\text { (2003); Fridolfsson } \\
\text { \& Ellegren (1999) }\end{array}$} & 10 & $95^{\circ} \mathrm{C}$ for $15 \mathrm{~s}$ & $\begin{array}{l}60-51{ }^{\circ} \mathrm{C} \text { for } 15 \mathrm{~s} \\
\text { (touchdown) }\end{array}$ & $72{ }^{\circ} \mathrm{C}$ for $10 \mathrm{~s}$ \\
\hline & & & & 30 & $95^{\circ} \mathrm{C}$ for $15 \mathrm{~s}$ & $50{ }^{\circ} \mathrm{C}$ for $15 \mathrm{~s}$ & $72{ }^{\circ} \mathrm{C}$ for $10 \mathrm{~s}$ \\
\hline & G3PDH & $\begin{array}{l}\text { G3P13b and } \\
\text { G3P14b }\end{array}$ & Prager et al. (2008) & 30 & $95^{\circ} \mathrm{C}$ for $15 \mathrm{~s}$ & $60{ }^{\circ} \mathrm{C}$ for $15 \mathrm{~s}$ & $72{ }^{\circ} \mathrm{C}$ for $10 \mathrm{~s}$ \\
\hline & MC1R & $\begin{array}{l}\text { IcorMSHR9 } \\
\text { and } \\
\text { IcorMSHR72 }\end{array}$ & Cheviron et al. (2006) & 30 & $95^{\circ} \mathrm{C}$ for $15 \mathrm{~s}$ & $67.5^{\circ} \mathrm{C}$ for $15 \mathrm{~s}$ & $72{ }^{\circ} \mathrm{C}$ for $10 \mathrm{~s}$ \\
\hline
\end{tabular}

*All PCR amplifications were started with an initial denaturation step of $1 \mathrm{~min}$ at $95{ }^{\circ} \mathrm{C}$ before commencing the cycles.

Bayesian analyses were performed using the program MrBAYES 3.1.2 (Huelsenbeck et al., 2001) via the CIPRES Science Gateway (Miller et al., 2010). For all markers, we pruned multiple haplotypes of the same species and location (Librado \& Rozas, 2009) to reduce computation time (see Table 2 for the frequencies of haplotypes that were found for each species and each location). Four Markov chains were run simultaneously for 20 million generations, with trees sampled every 100 generations. The trees generated prior to stationarity were discarded, and the consensus phylogeny and posterior probability of its nodes were determined from the last 175,000 trees in the chain. To check our results and reduce the risk of multiple optima, we repeated this process three times and compared resulting outputs. The program Tracer (Rambaut \& Drummond, 2007) was used to assess convergence diagnostics.

To assess which two alleles are present in the heterozygous nuclear sequences, we used algorithm-driven reconstruction of nuclear allele haplotypes (PHASE, implemented in DNAsP; Stephens \& Scheet, 2005; Librado \& Rozas, 2009). Median-joining haplotype networks were constructed (NETWORK v4.6.1.3; Forster et al., 2004) using the concatenated mtDNA dataset and separate nuclear markers that were phased with probability thresholds of 0.6 and 0.9 . As these two analyses yielded congruent results, we chose to use the default setting of 0.9 . We then identified recombinants using the four gamete test implemented in IMgc (Woerner et al., 2007). For approximate Bayesian computation ( $\mathrm{ABC}$ ) analyses (see below), we did not use any filtering, as (1) msABC allows for modelling recombination and (2) removing rare alleles is likely to interfere with demographic inferences and to bias summary statistic calculation (see Garrick et al., 2010).

\section{Approximate Bayesian computation analyses}

To test whether our data supported a model of admixture between F. aldabrana and F. madagascariensis from Assumption or Madagascar, we performed an ABC analysis (Fig. 2) (Beaumont et al., 2002). We considered four populations: F. madagascariensis from Madagascar and from Assumption, the putative hybrid population from Takamaka and F. aldabrana from other islands of Aldabra. In all models, we set divergence between the two species as a uniform prior (100,000-1,200,000 years ago based on Warren et al., 2012), with a generation time of 1 year (based on estimates of generation time available for F. aldabrana and other Foudia species; Frith, 1976; Safford \& Hawkins, 2013). Further parameters included current effective population sizes (uniform priors, 0-100,000 individuals except for the Madagascar population where the maximum size was set at 2,000,000 individuals), admixture rates from parental populations for Takamaka (uniform prior, 0.001-0.999) and initial population size for introgressed F. madagascariensis at Takamaka (uniform prior, 5-500 individuals).

We considered two possible immigration scenarios to explain the origin of F. madagascariensis on Aldabra (Figs 1 \& 2): a scenario of recent arrival from Assumption (and therefore time since admixture) between 5 and 37 years ago (scenario 1) and a recent-to-ancient arrival from Madagascar (scenario 2). Priors for times of arrival and admixture were set as at least 5 years ago but no more than the time of split between $F$. madagascariensis and F. aldabrana including the possibility of a non-human-mediated, natural colonization. A third possible scenario of human introduction to Aldabra (i.e. entirely human-mediated) can largely be ruled out as Aldabra is subject to strict controls regarding biosecurity and human access due to its World Heritage Site status. The 
Table 2 Frequencies of haplotypes found in the concatenated mtDNA and nuclear datasets, for each species/group of fodies (Foudia aldabrana, Foudia madagascariensis and putative hybrids) found at each of the locations in this study (Aldabra: Takamaka and other regions; Assumption; and other origins (as described in Table): only the individuals that share a haplotype with fodies caught on Aldabra and Assumption are shown). The two F. aldabrana (AF43 and AF73) clustering within the F. madagascariensis clade are underlined.

\begin{tabular}{|c|c|c|c|c|c|c|c|}
\hline \multicolumn{8}{|c|}{ Frequency; mtDNA concatenated dataset } \\
\hline \multirow[b]{2}{*}{ Haplotype ID } & \multirow[b]{2}{*}{ Total } & \multicolumn{2}{|c|}{ F. aldabrana (AF) } & \multicolumn{3}{|c|}{ F. madagascariensis (MF) } & \multirow{2}{*}{$\begin{array}{l}\text { Putative } \\
\text { hybrid (HF } \\
\text { Takamaka }\end{array}$} \\
\hline & & Takamaka & Other Aldabran islands & Takamaka & Assumption & Other & \\
\hline 1 & 15 & 2 & 12 & - & - & - & 1 \\
\hline 2 & 28 & 6 & 12 & - & - & - & 10 \\
\hline 3 & 1 & - & 1 & - & - & - & - \\
\hline 4 & 26 & $1(\mathrm{AF} 43)$ & - & 10 & 5 & 1 (NW Madagascar) & 10 \\
\hline 5 & 1 & 1 & - & - & - & - & - \\
\hline 6 & 1 & $1($ AF73) & - & - & - & - & - \\
\hline $7-8$ & 1 & 1 & - & - & - & - & - \\
\hline 9 & 2 & - & 2 & - & - & - & - \\
\hline $10^{*}$ & 14 & - & - & 4 & 4 & $\begin{array}{l}2 \text { (Seychelles; Praslin and } \\
\text { Frégate Island) }\end{array}$ & 4 \\
\hline $11-17$ & 1 & - & - & - & - & - & 1 \\
\hline 18 & 1 & - & - & - & 1 & - & - \\
\hline
\end{tabular}

Frequency; nuclear concatenated dataset

\begin{tabular}{|c|c|c|c|c|c|c|c|}
\hline \multirow[b]{2}{*}{ Haplotype ID } & \multirow[b]{2}{*}{ Total } & \multicolumn{2}{|c|}{ F. aldabrana (AF) } & \multicolumn{3}{|c|}{ F. madagascariensis (MF) } & \multirow{2}{*}{$\begin{array}{l}\text { Putative hybrid (HF) } \\
\text { Takamaka }\end{array}$} \\
\hline & & Takamaka & Other Aldabran islands & Takamaka & Assumption & Other Indian Ocean locations & \\
\hline $1 \dagger$ & 1 & - & 1 & - & - & - & - \\
\hline 2 & 5 & - & 5 & - & - & - & - \\
\hline 3 & 2 & - & 2 & - & - & - & - \\
\hline 4 & 3 & - & 1 & - & - & - & 2 \\
\hline 5 & 1 & - & 1 & - & - & - & - \\
\hline 6 & 4 & - & 1 & - & - & - & 3 \\
\hline 7 & 6 & 2 & 3 & - & - & - & 1 \\
\hline $8-9$ & 4 & 1 & 2 & - & - & - & 1 \\
\hline 10 & 1 & 1 & - & - & - & - & - \\
\hline 11 & 1 & 1 (AF43) & - & - & - & - & - \\
\hline $12-14$ & 1 & 1 & - & - & - & - & - \\
\hline 15 & 2 & 2 (AF73) & - & - & - & - & - \\
\hline 16 & 1 & 1 & - & - & - & - & - \\
\hline 17 & 3 & 1 & 1 & 1 & - & - & - \\
\hline $18-25$ & 1 & - & 1 & - & - & - & - \\
\hline 26 & 3 & - & - & - & - & - & 3 \\
\hline $27-47$ & 1 & - & - & - & - & - & 1 \\
\hline 48 & 1 & - & - & - & 1 & - & - \\
\hline 49 & 4 & - & - & 3 & 1 & - & - \\
\hline 50 & 1 & - & - & - & 1 & - & - \\
\hline 51 & 1 & - & - & 1 & - & - & - \\
\hline 52 & 7 & - & - & 3 & 4 & - & - \\
\hline 53 & 2 & - & - & 1 & 1 & - & - \\
\hline $54-58$ & 1 & - & - & 1 & - & - & - \\
\hline $59-60$ & 1 & - & - & - & 1 & - & - \\
\hline
\end{tabular}

*This haplotype was also shared with one individual of F. omissa (ID: O1712, Centr. Madagascar).

$\dagger$ This haplotype was also shared with two individuals of F. omissa (ID: LE24 and LE2, both Centr. Madagascar).

Assumption population of F. madagascariensis was introduced in 1977 from Mauritius, with 20-30 birds released (Prys-Jones et al., 1981). Foudia madagascariensis was introduced from Madagascar to Mauritius at least 235 years ago
(Cheke \& Hume, 2008). We included these events as fixed parameters in our models.

A total of 2 million datasets were simulated ( 1 million per scenario) using MSABC (Pavlidis et al., 2010) for the nuclear 
and the combined mitochondrial and nuclear data. $\mathrm{ABC}$ methods do not aim to recover the full coalescent information in the data, but compare summary statistics of simulated and observed datasets. For the mtDNA partition, we considered only the mitochondrial gene region ND3 as this dataset had fewer missing data than ATPase 6\&8 and should display the same genealogy, thus improving the precision in summary statistic calculation and making the analysis more conservative. Estimates of mutation rates for nuclear and mitochondrial data were taken from a previous Foudia study (Warren et al., 2012). Summary statistics included $F_{\text {st }}$, theta-Watterson estimator, Tajima's D, the number of segregating sites and proportions of alleles shared between subpopulations.

Each scenario was given the same uniform prior probability. Analyses were performed using the $\mathrm{R}$ package $\mathrm{ABC}$ (Csilléry et al., 2012). See Appendix S2 for more details on the $\mathrm{ABC}$ analyses.

\section{Morphological differentiation}

To identify differentiation between the three groups of fodies, a discriminant function analysis was performed (SPSS v.21, IBM SPSS Statistics, Armonk, NY, USA, 2012) using the morphological measurements described above (Table S1).

\section{RESULTS}

\section{Phylogenetic analysis of mitochondrial and nuclear data}

A PH test on the combined Foudia mtDNA markers (two partitions; $1223 \mathrm{bp}$ ) indicated that the gene regions did not differ in their phylogenetic signal $(P=0.99)$. A similar conclusion applied to the combined nuclear data (three partitions including CHD1Z; $1569 \mathrm{bp} ; P=0.30$ ). The highest level of resolution was present in the phylogenetic tree of the combined mtDNA markers (Fig. 3). Visual inspection of this tree supports accurate identification of birds by the field team (based on plumage and morphology), as all 14 individuals identified as F. madagascariensis at Takamaka displayed a F. madagascariensis haplotype (plus all 31 from other locations), and all 27 individuals from other, nonTakamaka locations identified as F. aldabrana (and from Warren et al., 2012) showed an F. aldabrana haplotype. Of the 32 individuals identified by the field team as putative hybrids, 21 displayed a F. madagascariensis haplotype and 11 an F. aldabrana haplotype. The tree is suggestive of hybridization in that two of the 12 birds from Takamaka identified as F. aldabrana displayed a F. madagascariensis mtDNA haplotype (AF43 and AF73; Fig. 3). Although Bayesian branch support is weak $(81 \%)$, the large number of F. madagascariensis haplotypes from Takamaka that fall in the same clade as the majority of Assumption samples (and a single sample from Madagascar) supports an Assumption origin for F. madagascariensis on Aldabra. The two hybrid F. madagascariensis $\times$ F. rubra offspring from Mauritius showed the same mtDNA haplotype as their F. rubra mother.

The haplotype networks of mtDNA and CHD1Z (Fig. 4a, b) reveal a clear separation between 'pure' F. aldabrana and F. madagascariensis individuals. For the maternally inherited mtDNA, most putative hybrids resemble F. madagascariensis, whereas in the sex-linked and thus male-biased inherited CHD1Z all but two hybrids share a haplotype with F. aldabrana. Only for CHDIZ is this difference of more hybrids resembling $F$. madagascariensis than $F$. aldabrana significant. $\left(\chi^{2}=17.16, P<0.001\right)$. This result is suggestive of a higher frequency of crosses between female F. madagascariensis and male F. aldabrana than crosses in the opposite direction. For the nuclear markers G3P and MC1R (Fig. 4c, d), this separation between F. aldabrana and F. madagascariensis is less clear, particularly in MC1R which shows high complexity with many interrelated haplotypes. This is likely due to incomplete lineage sorting, which is expected to be prevalent for slow-evolving autosomal markers at the evolutionary depth that we are concerned with here. Putative recombinant haplotypes were found dispersed across populations (Fig. 4), and no private recombinant haplotype could be found in the Takamaka population, suggesting that these events occurred before hybridization.

\section{Approximate Bayesian computation analyses}

Approximate Bayesian computation analyses displayed best support for the scenario where admixture occurred between 5 and 37 years ago between F. aldabrana and F. madagascariensis from Assumption, for both nuclear and complete datasets (Table 3). Misclassification tests suggested that our analysis distinguished clearly between models where birds came from Assumption or Madagascar (Fig. S1), with the best distinction coming from the nuclear dataset. As the highest support was found for the scenario where F. madagascariensis arrived from Assumption, we used this one for parameter estimation. Prediction errors (Csilléry et al., 2012) were high for almost every parameter (ranging from 0.17 to 1.06). No firm conclusions about the timing of admixture (i.e. 5 or 20 years ago) could be reached; however, admixture must have occurred after F. madagascariensis arrived on Assumption 37 years ago.

\section{Morphological differentiation}

There were morphological differences between birds identified by the Takamaka field team as F. madagascariensis, F. aldabrana and putative hybrids (Wilks' $\lambda=0.26$, $\chi^{2}=88.1$, d.f. $=10, P<0.001$; Fig. 5; Table S1). The analysis resulted in two discriminant functions accounting for $100 \%$ of variation, with the first function accounting for $89 \%$ of variation between groups. Overall, the proportions of individuals at Takamaka during the study period that were correctly classified into their original groups were F. aldabrana $=85.2 \%, \quad$ F. madagascariensis $=86.7 \% \quad$ and 


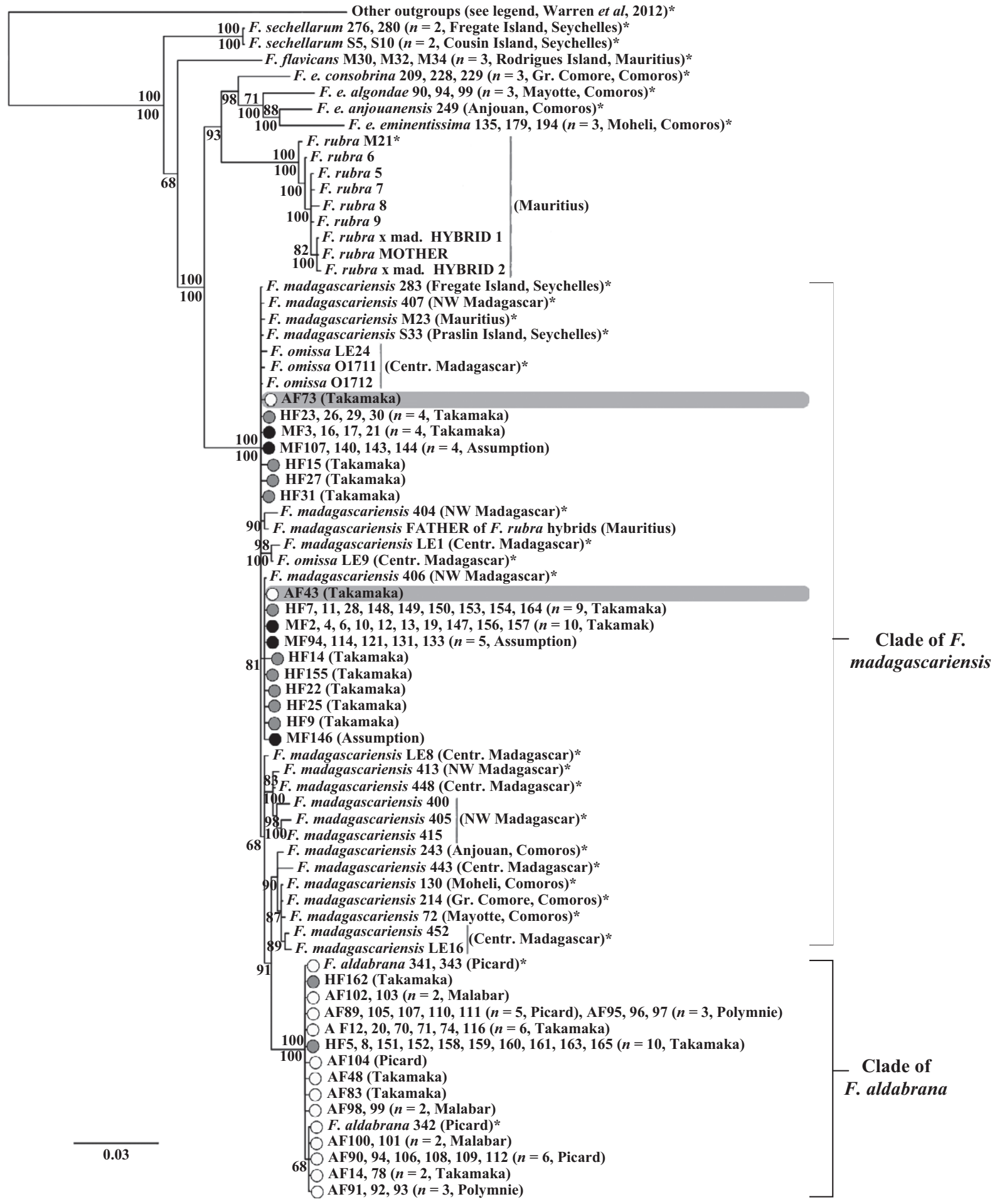

Figure 3 Bayesian analyses of Foudia concatenated mitochondrial (ATPase 6\&8 and ND3) data. Consensus of the last 175,000 trees after 20 million generations of the GTR + I model. Bayesian branch support values $(>60 \%)$ are indicated below bootstrap values (heuristic search, 1000 replicates) from a ML tree constructed using the $\operatorname{TrN}+$ I model (where $\operatorname{TrN}+\mathrm{I}$ is Tamura-Nei with invariable sites) as per Warren et al. (2012). Some nodes are represented by multiple individuals that share the same haplotype (sample sizes are given in brackets). Birds caught on Aldabra and Assumption and are marked with a circle to emphasize that they were identified in the field as Foudia aldabrana (white circle), Foudia madagascariensis (black circle) or hybrid (grey circle). The two Aldabra fodies falling in the Madagascar fody clade are highlighted in grey. The Mauritius fody hybrids are given in capitals. Outgroups that are not shown in the tree (upper node) include the genera Euplectes, Ploceus, Quelea and Malimbus from Africa, and Ploceus from Asia (Warren et al., 2012). Other samples that were used from the dataset of Warren et al. (2012) are marked with an asterisk. AF = Aldabra fody, $\mathrm{HF}=$ putative hybrid and MF = Madagascar fody. 

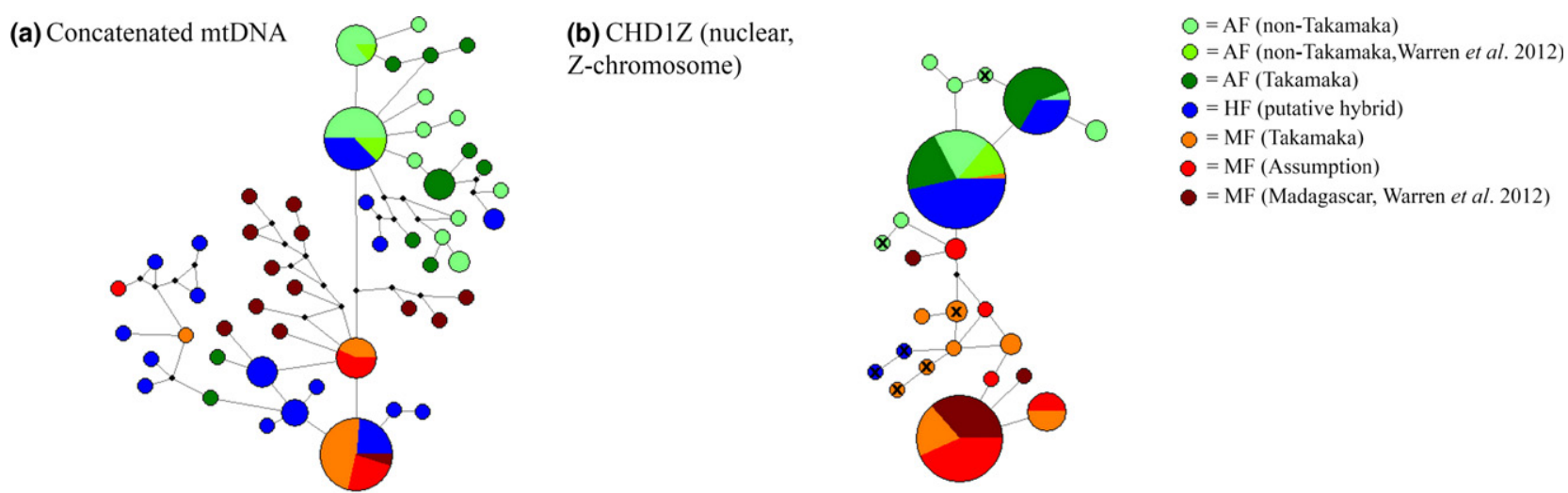

(c) G3P (nuclear)
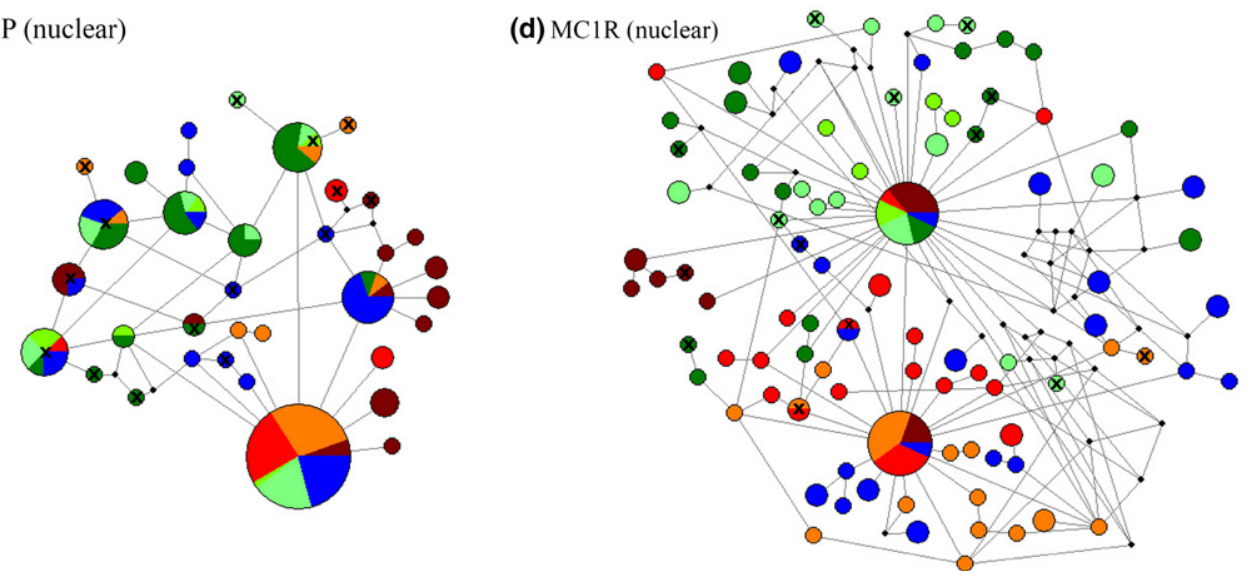

Figure 4 Median-joining haplotype networks for (a) the concatenated mtDNA dataset and the separate nuclear markers (b) CHD1Z, (c) G3P and (d) MC1R. Panel (a) derives from non-filtered data, whereas panels (b)-(d) derive from a phased dataset with a probability threshold of 0.9. The crosses indicate the positions of putative recombinant haplotypes and show that these are dispersed across populations. $\mathrm{AF}=$ Aldabra fody, $\mathrm{HF}=$ putative hybrid and $\mathrm{MF}=$ Madagascar fody.

Table 3 Posterior probabilities for each scenario derived from the approximate Bayesian computation analysis, for the (a) nuclear and (b) complete (nuclear + mitochondrial) dataset. Scenario 1: Invading birds come from Assumption and hybridize with Foudia aldabrana between 5 and 37 generations (years) ago. Scenario 2: Invading birds come from a Madagascar population and hybridize after the split between F. Aldabrana and F. Madagascariensis (see Fig. 2).

\begin{tabular}{llllll}
\hline & & & (b) Nuclear + mitochondrial data \\
\cline { 2 - 3 } & Scenario 1 & Scenario 2 & & Scenario 1 & Scenario 2 \\
\hline Rejection & $\mathbf{0 . 5 6 1 7}$ & 0.4383 & $\mathbf{0 . 8 2 9 8}$ & 0.1702 \\
Regression (neural net) & $\mathbf{0 . 9 1 1 8}$ & 0.0882 & $\mathbf{0 . 6 9 4}$ & 0.306 \\
\hline
\end{tabular}

The values in bold indicate that best support was found for scenario 1, for both nuclear and complete datasets.

hybrids $=74.1 \%$. For all measurements, $F$. aldabrana was the largest, and F. madagascariensis the smallest, while putative hybrids were intermediate (Table S1).

\section{DISCUSSION}

We show that an introduced passerine can impact upon a native species' genetic integrity through hybridization. Our results confirm that hybridization between introduced F. madagascariensis and endemic F. aldabrana on Aldabra is recent. The phylogenetic analyses provide a broader biogeo- graphic context and corroborate results from our coalescent analyses in indicating that F. madagascariensis on Aldabra originate from the introduced population on Assumption.

\section{Timing of admixture and origin}

The timing of admixture detected on Aldabra relative to human arrival provides a point of reference in determining its likely cause. If pre-human admixture had occurred (i.e. admixture dating to pre-settlement on Aldabra in the sixteenth century; Stoddart, 1971), then hybridization and subsequent 
Figure 5 Plot of the two canonical functions resulting from the discriminant function analysis, with their coefficients for each of the morphological variables. The two Aldabra fodies falling in the Foudia madagascariensis clade (ID AF43 and AF73) are encircled.

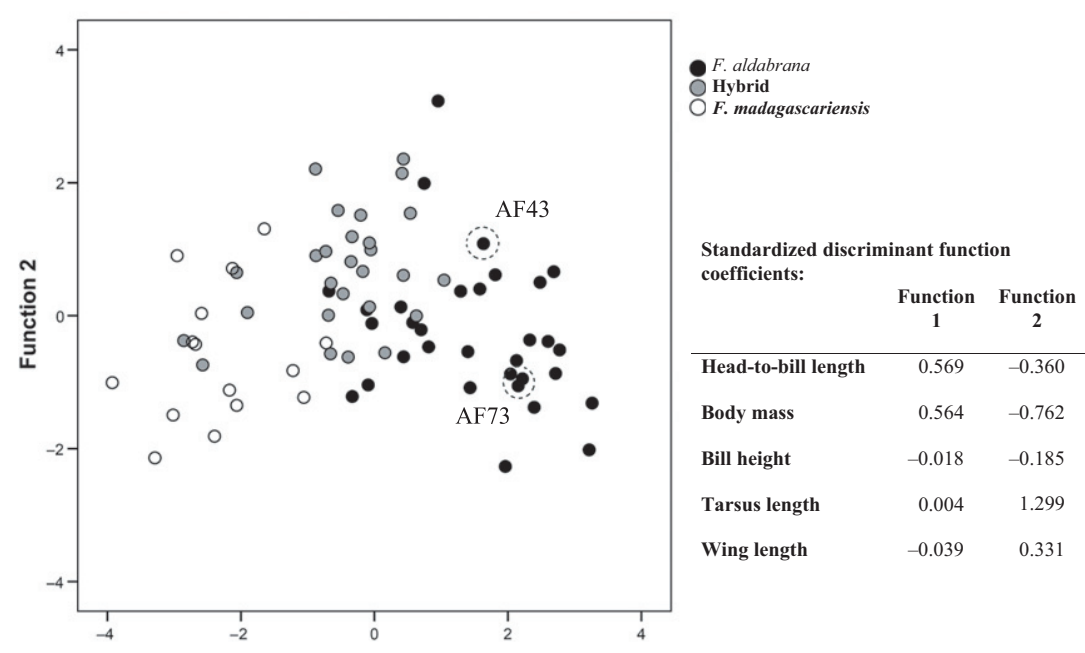

introgression of F. madagascariensis genes would have been the result of natural colonization. It is feasible that the F. aldabrana population could have experienced a steady historical trickle of F. madagascariensis from Madagascar since Foudia have been major colonizers of the western Indian Ocean region (Warren et al., 2012). Our analyses, however, do not support a scenario of strong pre-human gene flow on Aldabra but one of recent admixture. In addition, phylogenetic mismatches, in which $F$. aldabrana individuals fall outside the F. aldabrana clade (Figs $3 \& 4 \mathrm{a}$ ) and F. madagascariensis are nested within it, are restricted to birds from the Takamaka region. This pattern conforms to the known distribution of F. madagascariensis on Aldabra and suggests that introgression has not reached other areas. The absence of pre-human admixture, and the confirmation that Assumption is the origin of F. madagascariensis on Aldabra, provides a convincing case that the hybridization detected on Aldabra is not the result of natural colonization from Madagascar.

Although our genetic analysis does not rule out the possibility that the F. madagascariensis invasion on Aldabra followed the start of eradication activities on Assumption, it is more likely that their arrival pre-dated these activities and that their detection on Aldabra was a result of increased monitoring in the Takamaka area in early 2012. The population size, broad distribution and widely established nesting activity and territoriality of F. madagascariensis at Takamaka in 2012 only 2 months after the start of the Assumption eradication all suggest an earlier invasion. These facts, combined with the genetic results, suggest that invasion (which could have happened on more than one occasion) is unlikely to have been triggered by the Assumption eradication efforts, and we estimate the invasion to have occurred several years before the Assumption eradication programme started.

\section{Conservation decision-making}

Following the start of the F. madagascariensis eradication on Aldabra, signs of hybridization were observed in the field.
The emergency management response was culling of putative hybrids as well as F. madagascariensis individuals. Equally important was a rapid research response to inform and guide management. Our results have provided critical information for conservation decision-making on Aldabra and for future control efforts of introduced birds in areas with high risks of hybridization.

While eradication efforts might arguably have waited for genetic confirmation of hybridization, the risk of acting too late to control the spread of the introduced population across Aldabra's vast and inaccessible terrain was too high to delay immediate action. The eradication and genetic research were therefore initiated at the same time, with genetic results contributing to decision-making in the ongoing eradication programme and guiding identification in the field. This approach is ideal for conservation practitioners, as systematic appraisal of evidence can be effectively integrated into management, rather than relying on anecdotal or speculative information (Bauer \& Woog, 2011; Strubbe et al., 2011). Indeed, integration of genetic analyses of hybridization has been shown to have great value in the conservation management of other endangered species, such as the New Zealand endemic black stilt or kakī (Himantopus novaezelandiae; Steeves et al., 2010), the Hawaiian duck or koloa (Anas wyvilliana; Reed et al., 2012) and the black robin or Chatham Island robin (Petroica traversi; Ma \& Lambert, 1997).

Hybrid individuals may have either increased or reduced fitness relative to individuals of parental stock (Wright, 1932; Ryman, 1991; Baker et al., 2014). Introduction of new genetic material may improve the population's viability, particularly when levels of inbreeding are high (Pekkala et al., 2012). Conversely, high levels of hybridization between closely related species can also reduce population viability by diluting specifically adapted gene complexes, thereby destroying genetic integrity (outbreeding depression; Lande, 1999; Mank et al., 2004; Pekkala et al., 2012). The outcome of Foudia hybridization on Aldabra may depend on many 
factors, such as the extent of hybridization, the levels of inbreeding of $F$. aldabrana, their levels of adaptive genetic divergence and their vulnerability to losing adaptive potential due to genetic influx from F. madagascariensis. Regardless of potential population viability benefits, we consider the protection of the natural genetic integrity of F. aldabrana to be currently paramount. This purpose has become even more compelling since the recent acknowledgement that this lineage is a distinct species (Safford \& Hawkins, 2013). This conclusion, supported initially by phylogenetic analyses containing three $F$. aldabrana samples (Warren et al., 2012), is now strengthened by our analyses of a larger dataset of 24 additional 'pure' (non-Takamaka) F. aldabrana, which, together with the original three samples, form a monophyletic group with 100\% Bayesian branch support (Figs 3 \& S2). As outbreeding depression is expected to develop more strongly in increasingly diverged populations (Orr, 1995; Pekkala et al., 2012), the current confirmation of distinctiveness of $F$. aldabrana suggests that reduction in population viability after admixture might be more likely. Given that the expected impacts of hybridization are not always realized, comparing fecundity, survivorship and immunological parameters between hybrid, backcrossed individuals and 'pure' individuals of F. aldabrana would help to assess the potential fitness impacts to predict long-term population persistence (e.g. see Steeves et al., 2010). Such analysis, together with a better understanding of the F. aldabrana population's original genetic structure and vulnerability, would be a valuable direction for future research and would greatly help conserving Aldabra's unique fody species.

As expected from previous avian hybridization studies (Fitzpatrick, 2004), F. aldabrana $\times$ F. madagascariensis hybrids are not sterile, as they have been observed to successfully reproduce (SIF, unpubl. data). Some F. madagascariensis genetic material may therefore persist in the F. aldabrana population. However, the Takamaka F. aldabrana population comprises only a small part of the entire population of this species across Aldabra Atoll. Similarly, any remaining F1 or other hybrids will be vastly outnumbered by pure F. aldabrana individuals. Providing the eradication is successful, the impact of the 2012 presence of F. madagascariensis on the F. aldabrana genome is consequently expected to be small in the long term. Yet, without comprehensive genetic sampling of fody individuals on the atoll to detect cryptic hybrids, the risks of introgression from F. madagascariensis to $F$. aldabrana cannot be considered negligible. Our results are suggestive of a higher frequency of crosses between female F. madagascariensis and male F. aldabrana than crosses in the opposite direction, yet they should be verified with more loci and individuals. If confirmed, the results imply that the threat of hybridization posed by the presence of female F. madagascariensis is larger than that of males, suggesting that females should be high priority for eradication should any future human-mediated invasions occur of F. madagascariensis.

\section{CONCLUSION}

Although invasions are recognized as a leading threat to biodiversity (Dickman, 1996; Baker et al., 2014), there is limited direct evidence for negative impacts on biodiversity through invasions by birds (Blackburn et al., 2009; Kumschick \& Nentwig, 2010; Strubbe et al., 2011). Unlike the extensive knowledge base for invasive mammals and plants, the science and management of avian invasions is still in its infancy due to the relatively small number of successful invasive bird control operations (Kumschick \& Nentwig, 2010). Our phylogenetic and morphological analyses confirm that the arrival of an introduced bird can be detrimental for the conservation of unique genetic diversity as a result of hybridization. Given this study's confirmation of the distinctiveness of F. aldabrana, and from the perspective of protecting Aldabra's endemic avifauna, our findings confirm that treating Aldabra's F. madagascariensis population as introduced and acting accordingly was the appropriate course of action. Furthermore, our results validate the justification for eradicating F. madagascariensis from Assumption, as one potential threat to F. aldabrana has been confirmed (i.e. hybridization and erosion of unique genetic diversity). Genetic results can be applied in the field to set priorities and direct resources effectively. Prompt eradication action has already resulted in the removal of most F. madagascariensis and many hybrid individuals from Aldabra. Our research demonstrates the advantages of using molecular analyses as an integral part of biodiversity conservation programmes and applying a proactive approach to researching and managing invasive alien species.

\section{ACKNOWLEDGEMENTS}

We thank the staff and volunteers at Takamaka and Assumption for diligently collecting the samples and data for this research: Terence Mahoune, Jessica Moumou, Julio Agricole, Patrick Banville, Darryl Birch, Martijn van Dinther, Rebecca Filippin, Frankie Gamble, Oskar Guy, Laurent Leite, Stephanie Marie, Jamie McAulay, Glenn McKinley, Julio Moustache, Catherina Onezia, Nick Page, Lotte Reiter and Heather Richards. We are grateful to all SIF Aldabra and Head Office staff for logistical and administrative support; Islands Development Company and Assumption Island Manager $\mathrm{Mr}$ Chetty for support on Assumption; Christophe Thébaud, Josselin Cornuault and Boris Delahaie for aliquoting samples; the Mauritian Wildlife Foundation for providing samples, Simon Tollington, Rachel Bristol, Jim Labisko and Debbie Fogell for laboratory support and statistical feedback; Chris Kaiser-Bunbury for discussion; and the Natural History Museum of London (Tring; Robert Prys-Jones) for access to their fody collection. We thank two reviewers for their valuable comments on the manuscript. Financial support for the eradication was provided by UNESCO. Sequences have been 
submitted to NCBI GenBank (Accession numbers: KT333460-KT334009).

\section{REFERENCES}

Allendorf, F.W., Leary, R.F., Spruell, P. \& Wenburg, J.K. (2001) The problems with hybrids: setting conservation guidelines. Trends in Ecology and Evolution, 16, 613-622.

Anderson, E. (1949) Introgressive hybridization. John Wiley and Sons Inc, New York, NY.

Atkinson, I. (1989) Introduced animals and extinctions. Conservation for the twenty-first century (ed. by D. Western \& M. Pearl), pp. 54-75. Oxford University Press, New York, NY.

Baker, J., Harvey, K.J. \& French, K. (2014) Threats from introduced birds to native birds. The Emu, 114, 1-12.

Bauer, H.-G. \& Woog, F. (2011) On the "invasiveness" of non-native bird species. Ibis, 153, 204-206.

Beaumont, M.A., Zhang, W. \& Balding, D.J. (2002) Approximate Bayesian computation in population genetics. Genetics, 162, 2025-2035.

Blackburn, T.M., Lockwood, J.L. \& Cassey, P.B. (2009) Avian invasions: the ecology and evolution of exotic birds. Oxford University Press, New York, NY.

Cheke, A. \& Hume, J.P. (2008) Lost land of the dodo: the ecological history of Mauritius, Réunion and Rodrigues. T \& AD Poyser, London.

Chesser, R.T. (1999) Molecular systematics of the rhinocryptid genus Pteroptochos. The Condor, 101, 439-446.

Cheviron, Z.A., Hackett, S.J. \& Brumfield, R.T. (2006) Sequence variation in the coding region of the melanocortin1 receptor gene $(\mathrm{MC1R})$ is not associated with plumage variation in the blue-crowned manakin (Lepidothrix coronata). Proceedings of the Royal Society B: Biological Sciences, 273, 1613-1618.

Csilléry, K., François, O. \& Blum, M.G.B. (2012) abc: an R package for approximate Bayesian computation (ABC). Methods in Ecology and Evolution, 3, 475-479.

Dickman, C.R. (1996) Impact of exotic generalist predators on the native fauna of Australia. Wildlife Biology, 2, 185-195.

Dowding, J.E. \& Murphy, E.C. (2001) The impact of predation by introduced mammals on endemic shorebirds in New Zealand: a conservation perspective. Biological Conservation, 99, 47-64.

Farris, J.S., Källersjö, M., Kluge, A.G. \& Bult, C. (1995) Testing significance of incongruence. Cladistics, 10, 315-319.

Fitzpatrick, B. (2004) Rates of evolution of hybrid inviability in birds and mammals. Evolution, 58, 1865-1870.

Forster, P., Bandelt, H.J. \& Röhl, A. (2004) Network 4.2.0.1. Fluxus Technology Ltd. Software freely available at www.fluxus-engineering.com (accessed 1 July 2014).

Fowler, A.C., Eadie, J.M. \& Engilis, A. Jr (2009) Identification of endangered Hawaiian ducks (Anas wyvilliana), introduced North American mallards (A. platyrhynchos) and their hybrids using multilocus genotypes. Conservation Genetics, 10, 1747-1758.
Fridolfsson, A.-K. \& Ellegren, H. (1999) A simple and universal method for molecular sexing of non-ratite birds. Journal of Avian Biology, 30, 116-121.

Frith, C.B. (1976) A twelve-month field study of the Aldabran Fody Foudia eminentissima aldabrana. Ibis, 118, 155-178.

Garrick, R.C., Sunnucks, P. \& Dyer, R.J. (2010) Nuclear gene phylogeography using PHASE: dealing with unresolved genotypes, lost alleles, and systematic bias in parameter estimation. BMC Evolutionary Biology, 10, 118.

Grant, P.R. \& Grant, B.R. (1992) Hybridization of bird species. Science, 256, 193-197.

Haig, S.M. \& Allendorf, F.W. (2006) Hybrids and policy. The endangered species act at thirty: conserving biodiversity in human-dominated landscapes (ed. by J.M. Scott, D.D. Goble and F. Davis), pp. 150-163. Island Press, Chicago, IL.

Hansen, D.M., Olesen, J.M. \& Jones, C.G. (2002) Trees, birds and bees in Mauritius: exploitative competition between introduced honey bees and endemic nectarivorous birds? Journal of Biogeography, 29, 721-734.

Hatcher, M.J., Dick, J.T.A. \& Dunn, A.M. (2012) Disease emergence and invasions. Functional Ecology, 26, $1275-1287$.

Huelsenbeck, J.P., Ronquist, F., Nielsen, R. \& Bollback, J.P. (2001) Bayesian inference of phylogeny and its impact on evolutionary biology. Science, 294, 2310-2314.

IUCN (2014) The IUCN Red List of threatened species. http://www.iucnredlist.org (accessed 1 Dec 2014).

Kumschick, S. \& Nentwig, W. (2010) Some alien birds have as severe an impact as the most effectual alien mammals in Europe. Biological Conservation, 143, 2757-2762.

Lande, R. (1999) Extinction risks from anthropogenic, ecological, and genetic factors. Princeton University Press, Princeton, NJ.

Lanfear, R., Calcott, B., Ho, S.Y.W. \& Guindon, S. (2012) PartitionFinder: combined selection of partitioning schemes and substitution models for phylogenetic analyses. Molecular Biology and Evolution, 29, 1695-1701.

Librado, P. \& Rozas, J. (2009) DnaSP v5: a software for comprehensive analysis of DNA polymorphism data. Bioinformatics, 25, 1451-1452.

Ma, W. \& Lambert, D. (1997) Minisatellite DNA markers reveal hybridisation between the endangered black robin and tomtit. Electrophoresis, 18, 1682-1687.

Mank, J.E., Carlson, J.E. \& Brittingham, M.C. (2004) A century of hybridization: decreasing genetic distance between American black ducks and mallards. Conservation Genetics, 5, 395-403.

McCracken, K.G. \& Wilson, R.E. (2011) Gene flow and hybridization between numerically imbalanced populations of two duck species in the Falkland Islands. PLoS ONE, 6, e23173.

Meffe, G.K. \& Carroll, C.R. (1994) Principles of conservation biology, Sinauer, Sunderland, MA. 
Miller, M.A., Pfeiffer, W. \& Schwartz, T. (2010) Creating the CIPRES Science Gateway for inference of large phylogenetic trees. Gateway Computing Environments Workshop (GCE), 2010, pp. 1-8. IEEE.

Ödeen, A. \& Björklund, M. (2003) Dynamics in the evolution of sexual traits: losses and gains, radiation and convergence in yellow wagtails (Motacilla flava). Molecular Ecology, 12, 2113-2130.

Orr, H.A. (1995) The population genetics of speciation: the evolution of hybrid incompatibilities. Genetics, 139, 18051813.

Pavlidis, P., Laurent, S. \& Stephan, W. (2010) msABC: a modification of Hudson's ms to facilitate multi-locus ABC analysis. Molecular Ecology Resources, 10, 723-727.

Pekkala, N., E Knott, K., Kotiaho, J.S., Nissinen, K. \& Puurtinen, M. (2012) The benefits of interpopulation hybridization diminish with increasing divergence of small populations. Journal of Evolutionary Biology, 25, 2181-2193. Prager, M., Johansson, E.I. \& Andersson, S. (2008) A molecular phylogeny of the African widowbirds and bishops, Euplectes spp. (Aves: Passeridae: Ploceinae). Molecular Phylogenetics and Evolution, 46, 290-302.

Prys-Jones, R.P., Prys-Jones, M.S. \& Lawley, J.C. (1981) The birds of Assumption Island, Indian Ocean: past and future. Atoll Research Bulletin, 248, 1-16.

Rambaut, A. \& Drummond, A.J. (2007) Tracer v1.4. Software freely Available at: http://beast.bio.ed.ac.uk/Tracer (accessed 1 June 2014).

Reed, J.M., DesRochers, D.W., VanderWerf, E.A. \& Scott, J.M. (2012) Long-term persistence of Hawaii's endangered avifauna through conservation-reliant management. BioScience, 62, 881-892.

Rhymer, J.M. \& Simberloff, D. (1996) Extinction by hybridization and introgression. Annual Review of Ecology and Systematics, 27, 83-109.

Roberts, P. (1988) Introduced birds on Assumption Island a threat to Aldabra. Oryx, 22, 15-17.

Ryman, N. (1991) Conservation genetics considerations in fishery management. Journal of Fish Biology, 39, 211-224.

Safford, R. \& Hawkins, F. (2013) The birds of Africa: volume VIII: the Malagasy region: Madagascar, Seychelles, Comoros, Mascarenes. Bloomsbury Publishing, London.

Seehausen, O. (2004) Hybridization and adaptive radiation. Trends in Ecology and Evolution, 19, 198-207.

Simberloff, D. \& Boecklen, W. (1991) Patterns of extinction in the introduced Hawaiian avifauna: a reexamination of the role of competition. The American Naturalist, 138, 300-327.

Steeves, T.E., Maloney, R.F., Hale, M.L., Tylianakis, J.M. \& Gemmell, N.J. (2010) Genetic analyses reveal hybridization but no hybrid swarm in one of the world's rarest birds. Molecular Ecology, 19, 5090-5100.

Stephens, M. \& Scheet, P. (2005) Accounting for decay of linkage disequilibrium in haplotype inference and missingdata imputation. American Journal of Human Genetics, 76, 449-462.
Stoddart, D.R. (1971) Settlement, development and conservation of Aldabra. Philosophical Transactions of the Royal Society of London Series B, Biological Sciences, 260, 611-628.

Strubbe, D., Shwartz, A. \& Chiron, F. (2011) Concerns regarding the scientific evidence informing impact risk assessment and management recommendations for invasive birds. Biological Conservation, 144, 2112-2118.

Swofford, D.L. (2003) PAUP*: Phylogenetic Analysis Using Parsimony (* and other methods). Version 4. Sinauer Associates, Sunderland, MA.

Vaidya, G., Lohman, D.J. \& Meier, R. (2011) SequenceMatrix: concatenation software for the fast assembly of multigene datasets with character set and codon information. Cladistics, 27, 171-180.

Vallender, R., Robertson, R.J., Friesen, V.L. \& Lovette, I.J. (2007) Complex hybridization dynamics between goldenwinged and blue-winged warblers (Vermivora chrysoptera and Vermivora pinus) revealed by AFLP, microsatellite, intron and mtDNA markers. Molecular Ecology, 16, 2017-2029.

Veitch, C.R. \& Clout, M.N. (2002) Turning the tide: the eradication of invasive species. Proceedings of the International Conference on Eradication of Island Invasives, University of Auckland, Auckland. IUCN, Gland, Switzerland and Cambridge, UK/IUCN/SSC Invasive Species Specialist Group, Auckland, New Zealand. Occasional Paper of the IUCN Species Survival Commission No. 27.

Vitousek, P.M., Loope, L. \& Adsersen, H. (1995) Islands: biological diversity and ecosystem function. Springer-Verlag, Berlin.

Warren, B.H., Bermingham, E., Bourgeois, Y., Estep, L.K., Prys-Jones, R.P., Strasberg, D. \& Thébaud, C. (2012) Hybridization and barriers to gene flow in an island bird radiation. Evolution, 66, 1490-1505.

Woerner, A.E., Cox, M.P. \& Hammer, M.F. (2007) Recombination-filtered genomic datasets by information maximization. Bioinformatics, 23, 1851-1853.

Wright, S. (1932) The roles of mutation, inbreeding, crossbreeding, and selection in evolution. Proceedings of the Sixth International Congress of Genetics Eds. D.F. Jones \& R. Robbins, pp. 356-366. Genetics Society of America, New York.

\section{SUPPORTING INFORMATION}

Additional Supporting Information may be found in the online version of this article:

Appendix S1 Molecular methods: DNA extraction, PCR amplification, sequencing and sexing.

Appendix S2 Details of the ABC analyses.

Table S1 Biometric measurements of the Aldabra fodies, Madagascar fodies and putative hybrids.

Figure S1 Histograms of model misclassification. 
Figure S2 Bayesian analyses of Foudia concatenated mtDNA data, without fodies from the Takamaka region.

Figure S3 Goodness of fit plots for the nuclear and the complete dataset.

\section{BIOSKETCH}

Janske van de Crommenacker is an ecologist with primary interests in using cross-disciplinary research methods to help with the conservation of endangered island species and systems. In her role as Scientific Coordinator and Researcher on Aldabra Atoll, she used molecular methods to address conservation-linked questions. She received a Ph.D. in the ecophysiology of the Seychelles warbler, investigating patterns of oxidative stress, physiology and fitness in this endangered island bird species.

The Seychelles Islands Foundation (SIF) is a self-funded, charitable trust established in 1979 that has a mandate to manage and protect the two World Heritage Sites of Seychelles: Aldabra Atoll and Vallee de Mai and their biodiversity.

The Durrell Institute of Conservation and Ecology (DICE) at the University of Kent (UK), UK, where the molecular work for this study was carried out, has the mission to conserve biodiversity and the ecological processes that support ecosystems, and improve conservation management and policy through high-impact applied conservation research.

Author contributions: N.B., F.F.-D. and J.v.d.C. conceived and planned the project; J.v.d.C. and field staff collected the data; J.v.d.C. conducted the laboratory work; J.G. supervised the laboratory work; J.v.d.C., B.H.W., Y.X.C.B. and H.J. analysed the data; all authors contributed to the writing of the manuscript, which was led by J.v.d.C.

Editor: Jeremy Austin 